\title{
O necroliberalismo, bolsonaro 'vírus mental' e a pandemia da COVID-19 como casos de saúde pública: o real resiste?
}

\author{
$O$ real resiste \\ É só pesadelo, depois passa \\ Na fumaça de um rojão \\ Miliciano não existe \\ Torturador não existe \\ Fundamentalista não existe \\ Terraplanista não existe \\ Monstro, vampiro, assombração \\ $O$ real resiste \\ É só pesadelo, depois passa \\ Múmia, zumbi, medo, depressão \\ Não, não, não, não \\ Não, não, não, não \\ Não, não, não, não \\ (Música de Arnaldo Antunes - O real resiste)
}

A expressão 'o real resiste' é um recado aos súditos de Bolsonaro e à direita fascista, que negam a concreticidade desse poema. É nesses termos, que, em nossos editoriais, vimos denunciando o processo de Golpe de Estado que deu materialidade ao impeachment da ex-Presidenta Dilma Rousseff, iniciado em 2013, com as chamadas Jornadas de Junho, e rematado com a chegada ilegal do traidor Michel Temer ao poder. Em todas as edições de 2019, particularmente na última, de outubro, a revista também acompanhou a subida do 'Capetão Corona' à rampa do Palácio da Alvorada. Todavia, em tempos sombrios, que refletem as destruições de Bolsonaro e a consequente falência do Brasil em termos econômicos e políticos, torna-se conveniente lembrar que a estratégia do Golpe de 2016 foi engendrada sob a forma político-militar das guerras híbridas, ${ }^{1}$ que promovem tomadas de Estado através da ação coordenada entre elementos diversos, como a insurgência política, as guerras convencional e irregular, a ingerência sobre os processos eleitorais, a divulgação de fake news e a prática de lawfare. Nesse imbróglio, tiveram um grande papel pela aliança das forças políticas burguesas, os militares, as mídias e seus conglomerados (Rede Globo e outros), os partidos de direita e ultradireita, a Fiesp, o STF, os neopentecostais e, por fim, as forças imperialistas norteamericanas, representadas por Trump.

$\mathrm{Na}$ verdade, todos eles foram responsáveis pelo Golpe, desde os setores da classe dominante e da classe média protofascista até os pobres de direita; todos são 'cúmplices', no dizer de Eliane

${ }^{1}$ KJORYBKO, Andrew. Guerras híbridas: das revoluções coloridas aos golpes. São Paulo: Expressão Popular, 2018. 
Brum. $^{2}$ É nessa conjuntura que se acentua o protofascismo brasileiro, que contém determinados aspectos sociais, políticos e ideológicos do nazifascismo. ${ }^{3} \mathrm{~A}$ onda de barbáries que estamos atravessando no presente, em termos de destruição das políticas públicas e sociais, as quais vimos fenecer a cada dia, são fruto também do lawfare e das guerras híbridas locais e internacionais. Todo esse conluio que forjou o neoliberalismo autoritário instalado no país a partir das eleições de 2018 só foi possível graças à cumplicidade da maioria desses sujeitos e de parte da população de eleitores cujo voto foi motivado pelas diversas fake news ${ }^{4}$ que circularam nas redes sociais e nos aplicativos de conversa. Trata-se de um fenômeno mundial; diz respeito ao crescimento da ultradireita em todo mundo, em especial na América Latina, que, mesmo sob protestos da esquerda, viu-se surpreendida por discurso exacerbadamente nacionalista e pseudomoralista. Esses candidatos populistas, a exemplo de Bolsonaro, cada qual a sua maneira, aproveitaram o descontentamento de parte de seus eleitores em prol de bandeiras que prometem a democracia liberal, mesmo sem direitos. ${ }^{5}$

Desde o início do mandado de Bolsonaro, a Motrivivência tem tentado descrever as destruições causadas por esse psicopata no poder, que, sintetizando neoliberalismo, autoritarismo, nazismo, fascismo, entre outras perspectivas anticivilitatórias, termina por desvendar a cada dia que o 'real resiste', sim, principalmente eivado de necropolítica ${ }^{6}$, no âmbito do neoliberalismo letal ${ }^{7}$ também chamado necroliberalismo.

$\mathrm{Na}$ edição passada e também nas anteriores, denunciamos como o inominável Bolsonaro (psicopata, vírus mental, câncer do mundo, etc.) vem destruindo, desde janeiro de 2019, a ciência, a educação (em especial as universidades públicas), as instituições em geral, a previdência, os direitos trabalhistas, a cultura, o meio ambiente (destruição da Amazônia e tentativas de aniquilamento dos indígenas e quilombolas) e colocando em risco a soberania nacional, ao entregar nosso patrimônio e nossa riquezas de forma subserviente ao imperialismo norte-americano de Trump (Pré-sal, Base de Alcântara, Embraer, entre outras), além de privatizar setores estratégicos, como aeroportos, portos, escolas, universidades, estradas e outras empresas e serviços importantes para a segurança nacional. Assim, de janeiro de 2018 até os dias atuais, vivemos cotidianamente um pesadelo, uma verdadeira 'tormenta', ou seja, a defesa da tortura e a volta do AI-5, inclusive com a anuência de setores das forças armadas, sem contar com os assassinatos, provavelmente efetuados por milicianos, de lideranças de partidos de esquerda (Marielle Franco, membros de movimentos sociais e sindicais, ameaças de morte e perseguições aos supostos inimigos da esquerda - comunistas e petistas), além de outras violências simbólico-reais. Essas são as imagens macabras de um dos mais improváveis governos que o Brasil já viveu, cujas peculiaridades e dinâmica, em muitos aspectos, são comparáveis às iniquidades da Ditadura Militar. ${ }^{8}$

Todo esse processo, evocado nos nossos editoriais, pretende alertar aos que militam nas salas de aula e quadras, nos ginásios de esporte e campos de futebol, na área de Educação Física e para além dela, sobre a necessidade de combater as ideias e práticas do necroliberalismo (autoritário e letal) em tempos de declínio e crise do capitalismo, principalmente em tempos de pandemia. Aliás, à

${ }^{2}$ BRUM, Eliane. Os cúmplices. El País, [S. l.], 1 jan. 2020. Disponível em: https://bit.ly/2JvQr9h. Acesso em: 25 mar. 2020

${ }^{3}$ LYRA, Rubens Pinto. O protofascismo brasileiro. Carlos Lima, Feira de Santana, 1a abr. 2020. Disponível em: https://bit.ly/39HUOZB. Acesso em: 2 abr. 2010.

${ }^{4}$ BRUM, Eliane. Os cúmplices. El País, [S. l.], 1 jan. 2020. Disponível em: https://bit.ly/2JvQr9h. Acesso em: 25 mar. 2020

5 MOUNK, Yascha. O povo contra a democracia: por que a liberdade corre perigo e como salvá-la. São Paulo: Companhia das letras, 2019.

${ }^{6}$ MBEMBE, Schille. Necropolítica: biopoder, soberania, estado de exceção. São Paulo: N’1 Edições, 2018 , p. 3.

7 OLIVEIRA SÁ, Thiago Antônio. Neoliberalismo letal. Jornal GGG, [S. l.], 26 mar. 2020. Disponível em: https://bit.ly/2Uy1pRO. Acesso em: 26 mar. 2020.

${ }^{8}$ OYAMA, Thaís. Tormenta: O governo Bolsonaro: crises, intrigas e segredos. São Paulo: Companhia das Letras, 2020. 
guisa de lembrete, vale destacar que o presidente Bolsonaro tripudia diuturnamente a inteligência e a opinião públicas ao dizer que a COVID-19 não passa de uma 'gripezinha' e que ele não pegará nada, pois é 'ex-atleta'. Essa sandice anticientífica e irresponsável foi duramente contestada e desmentida pelo GTT Atividade Física e Saúde do CBCE, através de uma Moção de Repúdio ao pronunciamento do presidente Bolsonaro sobre o coronavírus. ${ }^{9}$ Com todo esse arsenal de destruição do Estado brasileiro, Bolsonaro não pode ser chamado simplesmente de irresponsável, ignorante e louco. Aliás, não se trata de um louco, nem de um 'maluco' - para não ofender os 'malucos beleza'. Ele é uma peça na maquinaria protofascista; na verdade, é um ignorante 'líder de torcida', de uma gangue, milícia, facção, seita, que só se preocupa em manter a união inquebrantável de seu grupo de vassalos e adoradores empresariais, neopentecostais, entre outros grupos sociais, todos 'adoradores do Deus Mercado', da mão invisível do mercado. Em suma, a suposta ignorância ou loucura do antipresidente "[...] é puro pragmatismo capitalista, sem vocação humanitária nem responsabilidade cidadã; ele está friamente entregando a encomenda aos donos do capital, aos donos do país, como compete a qualquer matador de aluguel". ${ }^{10}$

Apesar de todas as destruições engendradas por esse ser humano deplorável e obscurantista, seus apoiadores e seguidores fanáticos não baixaram a guarda e continuam seguindo os rastros de ignorância e ódio do suposto 'mito' de 'hormônio assassino'. Eles precisam reconhecer que a 'arminha' na mão e a licença para matar supostos inimigos, entre os quais opositores de esquerda, indígenas, GLBTQs, quilombolas, trabalhadores empobrecidos, populações de rua e outros cidadãos, mostra-nos que "O mundo - caquinho de vidro - tá cego do olho, tá surdo do ouvido, o mundo tá muito doente. O homem que mata, o homem que mente". ${ }^{11}$

Esses apoiadores que vão às ruas fazer carreatas são oriundos, provavelmente, dos seguintes segmentos sociais: as elites empresariais, a classe média endividada, os pequenos e médios empreendedores, militares da reserva remunerada saudosos da ditadura, e os chamados 'pobres de direita'. Todos esses segmentos, tanto no Brasil quanto em outros países do mundo, seguindo um movimento de ultradireita, têm feito os cientistas sociais refletirem sobre o fenômeno do "povo contra a democracia". Estamos nos referindo à ideia de democracia liberal, que se constitui numa forma de governo cujos pressupostos apregoam que o Estado deve se abster de interferir na esfera de direitos dos cidadãos e na economia, visto que esta seria dotada de mecanismos de autorregulação. ${ }^{12}$

E, nesse sentido, fica a seguinte pergunta: por que os 'pobres de direita', incluindo a classe média, insistem em engrossar as fileiras dos defensores da democracia liberal, sem direitos e liberdade, ao invés de se enveredar pelos valores humanitários, em favor de uma democracia emancipatória e anticapitalista?

Ainda na edição passada, dedicamos grande parte do editorial à nossa identidade com o potencial de resistência do Chile e de outros países da América Latina, os quais têm se empenhado em combater, veementemente, a democracia liberal. Nesta edição, a luta continua, apesar desses três vírus: Bolsonaro, com seu senso comum tosco e anticientífico, o neoliberalismo e o coronavírus. Os desafios serão hercúleos, no sentido de encarar essa guerra com conhecimento científico, solidariedade de classe, generosidade e capacidade para transformar essas distopias em utopias: o real deve resistir mais diante de tanta iniquidade social, econômica, política e cultural.

$$
* * *
$$

${ }^{9}$ COLÉGIO BRASILEIRO DE CIÊNCIAS DO ESPORTE. Grupo de Trabalho Temático - Atividade Física e Saúde. Moção de Repúdio ao pronunciamento do presidente Bolsonaro sobre o coronavírus. CBCE, Porto Alegre, 25 mar. 2020. Disponível em: https://bit.ly/3bFRZJO. Acesso em: 25 mar. 2010.

${ }^{10}$ OLIVEIRA SÁ, op. cit.

11 Trecho da música $O$ mundo, de Zeca Baleiro.

${ }^{12}$ MOUNK, 2019, p. 37. 


\section{Crise do capital: o neoliberalismo está chegando ao fim?}

Nesses momentos de crise do capitalismo neoliberal, temos que reconhecer que

[...] o fluxo do sangue do capital flui através do corpo político de todas as sociedades que chamamos de capitalistas, que se espalha, às vezes como um filete e outras vezes como uma inundação, em cada canto e recanto do mundo habitado. É graças a esse fluxo que nós, que vivemos no capitalismo, adquirimos nosso pão de cada dia, assim como nossas casas, carros, telefones celulares, camisas, sapatos, e todos os outros bens necessários para garantir nossa vida no dia a dia. A riqueza a partir da qual muitos dos serviços que nos apoiam, entretêm, educam, ressuscitam ou purificam são fornecidos é criada por esses fluxos. Ao tributar esses fluxos, os Estados aumentam seu poder, sua força militar e sua capacidade de assegurar um padrão de vida adequado aos seus cidadãos. Se interrompemos, retardamos ou, por exemplo, suspendemos o fluxo, deparamos com uma crise do capitalismo em que o cotidiano não pode mais continuar no estilo a que estamos acostumados. ${ }^{13}$

Antes de mais nada, antes de refletir sobre a crise do capital, há a necessidade de evocar as principais crises que assolaram e vêm assolando esse modo de produção, trazendo destruição, sofrimentos, dilemas, constrangimentos, guerras e mortes para a sociedade humana. Esse fenômeno tem como epicentro a economia global, que nos últimos cem anos, através de quatro grandes crises, vem sofrendo rupturas que influenciam a sociabilidade e agudizam a luta de classes e os conflitos entre capital e trabalho, aumentando, consequentemente, as desigualdades sociais: a Grande Depressão de 1929, o Choque do Petróleo, na década de 70, a Grande recessão de 2008 e a atual pandemia causada pelo coronavírus, em fevereiro e março de $2020 .{ }^{14}$

Com base nessas reflexões, urge compreender a reprodução e o fluxo do capital, seus caminhos cíclicos e sinuosos, sua estanha lógica acumulativa, sua destruição criativa, enfim, sua estranha lógica de comportamento. Nesse sentido, é de suma relevância entender as condições em que ele se reproduz e também as condições objetivas sob as quais, teimosamente, apesar dos pesares, tentamos construir a vida para além de sua lógica. ${ }^{15}$ Esse procedimento é fundamental, considerandose que, nos primórdios do capitalismo, economistas políticos de todas as tendências se esforçaram e ainda hoje o fazem - para decifrar os fluxos do capitalismo e o modo como ele funciona e se reproduz. Entretanto, nos últimos tempos, apesar dessas reflexões, "nos afastamos do exercício desse tipo de compreensão crítica", necessária e permanente. Apesar do grande esforço dos intelectuais, ainda insistimos em construir "[...] modelos matemáticos sofisticados, analisando dados sem fim, investigando planilhas. Com isso, [...] dissecamos em detalhes qualquer concepção de caráter sistêmico do fluxo de capital sob um monte de papéis, relatórios, previsões". ${ }^{16}$

Grosso modo, podemos dizer que, na perspectiva da crise da sociedade capitalista, as crises do capital podem ser concebidas como o colapso dos princípios básicos de funcionamento da sociedade. Colapso que é gerado pelo processo de acumulação, determinado pela tendência crescente da taxa de juros. Entretanto, há uma diferença entre as crises e os colapsos parciais e as crises que conduzem à transformação de uma sociedade ou formação social. As crises ou colapsos sociais dizem

\footnotetext{
${ }^{13}$ HARVEY, David. O enigma do capital e as crises do capitalismo. São Paulo: Boitempo, 2011, p. 7.

${ }^{14}$ BOUGTHON, James. A crise global clama por uma liderança mundial. Veja, [S. l.], 26 mar. 2020. Disponível em: https://bit.ly/2wVgT9t. Acesso em: 26 mar. 2020.

${ }^{15}$ HARVEY, 2011, p. 7.

${ }^{16}$ Ibid., loc. cit.
} 
respeito a fenômenos como os ciclos econômicos, que abrangem surtos de prosperidade aparentemente intermináveis, seguidos de graves declínios da atividade econômica, constituindo-se numa doença crônica do capitalismo.

As crises que conduzem à transformação da sociedade ou formação social são a tradução do enfraquecimento do seu princípio organizador ou nuclear, ou seja, a erosão ou destruição daquelas relações sociais que determinam o alcance e os limites da transformação das atividades política, econômica, entre outras. Em suma, podemos inferir que a crise é constitutiva do modo de produção capitalista, não existindo, portanto, capitalismo sem crise. As crises sempre existirão, principalmente pelo fato de a sociedade capitalista ser marcada pela contradição antagônica entre as classes sociais (proletariado e burguesia). A crise do capitalismo atual é chamada de crise estrutural do capital. ${ }^{17}$

Istivan Mészáros, através de densa investigação, debruçando-se sobre o século XX, faz uma profunda e devastadora crítica às engrenagens que caracterizam o sistema sociometabólico do capital. $\mathrm{O}$ autor constata que a expansão do sistema do capital não tem limites, convertendo-se numa processualidade incontrolável e profundamente destrutiva. E isso pode ser constatado na ganância dos capitalistas brasileiros (bilionários, banqueiros, comerciantes e outros), no que se refere à acumulação primitiva de capital em meio ao crescimento e acirramento das desigualdades de classe social. Portanto, não há limites para o acúmulo de riqueza forjado na exploração do trabalho alheio ou para a defesa da propriedade privada dos meios de produção. ${ }^{18}$

Tudo isso se dá a partir do que Marx chamou de mediações de segunda ordem, isto é, quando tudo passa a ser controlado pela lógica de valorização do capital, que não leva em consideração imperativos humano-societais vitais. A produção e o consumo supérfluos acabam por gerar a corrosão do trabalho, o que tem como consequência a precarização e o desemprego estrutural, além de impulsionar uma destruição da natureza em escala planetária jamais observada anteriormente. A expansão destrutiva do sistema do capital se realiza pela busca crescente e desmedida de mais-valor, pautando-se pela superfluidade e descartabilidade sem limites. Todo esse processo, baseado num longo período, compreendido pelos ciclos de que falamos há pouco, fez com que o sistema viesse a assumir, de acordo a formulação de Mészáros, a forma de uma crise endêmica, cumulativa, crônica e permanente. Esse fato, devido ao espectro de destruição global, impele-nos a buscar outra alternativa societal, visando à construção de um novo modo de produção e de um novo modo de vida, cabal e frontalmente contrário à lógica destrutiva do capital hoje dominante. ${ }^{19}$

A crise de dominação do capital se alastra com seus problemas e acirra contradições cada vez mais explosivas. Nesse sentido, há uma tendência objetiva, inerente à natureza do capital e ao seu crescimento dentro de um sistema global, conjugada com sua contração e sua sempre articulação com a ciência e tecnologia, cujos efeitos abalam e tornam anacrônica a subordinação socioestrutural do trabalho ao capital. Todavia, num mundo constituído por uma multiplicidade de sistemas sociais conflitantes e em mútua interação, em contraste com o mundo fantasioso das escaladas e desescaladas do tabuleiro de xadrez, o precário status quo global caminha certamente para uma ruptura. Em vista disso, ficam as seguintes reflexões: a questão não é se haverá ruptura ou não, mas sim por que meios o capital se organizará através do trabalho humano, seja de adultos ou de crianças e jovens, com o fim de extrair mais-valia. Todo esse processo pode ser verificado em diferentes crises cíclicas do capital, ocorridas em distintos períodos da história. A atual crise estrutural do capital, como mencionado, é uma crise longeva, duradoura, sistêmica e estrutural, sobretudo nos séculos XX e XXI. A partir de suas contradições antagônicas de classe entre proletariado e burguesia (desigualdades sociais) e entre capital e trabalho (desemprego, subemprego), está destinada a piorar

\footnotetext{
${ }^{17}$ ANTUNES, Ricardo. Introdução: substância da crise. In: MÉSZÁROS, Istvan. A Crise Estrutural do Capital. São Paulo: Boitempo, 2011, p. 11.

18 Ibid., loc. cit.

${ }^{19}$ Ibid., loc. cit.
} 
consideravelmente no estágio atual de desenvolvimento. Ela pode vir a se tornar mais aguda no sentido de invadir não apenas o mundo das finanças globais, mais ou menos parasitárias, mas também todos os domínios da nossa vida econômica, social e cultural. ${ }^{20}$

Cabe perguntar: o capital se romperá por meios militares, através de guerras híbridas ou mesmo de guerras devastadoras, como já vem ocorrendo, ou haverá válvulas sociais adequadas para o alívio das crescentes tensões sociais, que hoje estão em evidência mesmo nos cantos mais remotos do nosso espaço social global? Esse movimento contraideológico e revolucionário só será possível a partir do sucesso ou da criação dos necessários movimentos estratégicos e de instrumentos capazes de assegurar uma efetiva transição para uma sociedade socialista, na qual a humanidade possa encontrar a unidade de que necessita para a sua simples sobrevivência. Em suma: é necessário que, no decurso do desenvolvimento humano, a função do controle social não seja alienada do corpo social e transferida para o capital. Este não pode ter o poder de aglutinar os indivíduos num padrão hierárquico estrutural e funcional, de acordo com o critério de maior ou menor participação no controle da produção e da distribuição.

\title{
Neoliberalismo letal, necropolítica e 'a podridão da elite brasileira em meio à pandemia'
}

\author{
O que vemos, na atualidade, são "Óbitos, óbitos, óbitos, cada vez mais óbitos, óbitos, \\ óbitos. Nunca é demais. Assinam assassinatos e deliberam as guerras. Exercem os \\ seus mandatos. Alimentando misérias." 21
}

A necropolítica é a política da morte, adaptada pela necropolítica do Estado necroliberal e protofascista. Nessa perspectiva, em meio à pandemia da COVID-19, a expressão máxima da soberania reside, por parte do Estado, em grande medida, no seu poder de ditar quem pode viver (os jovens) e quem deve morrer (os velhos). Por essa razão, no governo Bolsonaro, "[...] matar ou deixar viver constituem os limites da soberania do sistema - seus atributos fundamentais". Em suma, “[...] ser soberano é exercer controle sobre a mortalidade e definir a vida como implantação e manifestação do poder", segundo as palavras de Mbembe. ${ }^{22}$ Um exemplo disso reside no fato de que o vírus não afeta todas as pessoas de maneira igual, ou seja, há a ideia de priorizar o tratamento de jovens e deixar os mais idosos morrerem. Há ainda aqueles que, como o presidente Jair Bolsonaro, insistem em que a economia não pode parar, mesmo que parte da população precise morrer para garantir essa produtividade. ${ }^{23}$

A necropolítica não é um episódio, não é um fenômeno que foge à regra. Ela é a regra, quando se assiste ao presidente Bolsonaro defender o fim da quarentema e a retomada da economia, mandando todos à rua para não haver prejuízos econômicos, desemprego, etc. A materialização dessa política se dá pela expressão da morte, do extermínio e do ódio aos supostos inimigos políticos - de classe, gênero, cultura e geração. Em contrapartida, pensamos que "[...] o Estado não é para matar ninguém, ele é para cuidar, prover e não para cortar vidas e, por isso, contar os mortos de maneira fria e calculista em nome dos números da Bolsa de valores. Todavia essa não é a percepção dos

${ }^{20}$ ANTUNES, 2011, p. 3.

21 Trecho do poema Óbitos, de Arnaldo Antunes.

${ }^{22}$ MBEMBE, 2018, p. 3.

${ }^{23}$ BEREITO, Diogo. Pandemia democratizou poder de matar, diz autor da teoria da necropolítica. Folha de São Paulo, São Paulo, 30 mar. 2020. Disponível em: https://bit.ly/3aLge9q. Acesso em: 31 mar. 2020. 
capitalistas brasileiros e do presidente Bolsonaro, quando está em pauta a necessidade de se dizer quarentena, para exterminar o COVID-19". ${ }^{24}$

O que vemos hoje é um Estado que adota a política da morte, o uso ilegítimo da força, o extermínio, a política do ódio e do descaso para com a classe trabalhadora que vive na pobreza. Tudo isso pode ser visto, por exemplo, nas favelas e comunidades do Rio de Janeiro, nas periferias das grandes e médias cidades brasileiras. Não há nenhum tipo de serviço de inteligência, de combate à criminalidade. $\mathrm{O}$ que se tem, no liberalismo letal, é a perseguição daqueles considerados perigosos, tanto do ponto de vista de classe, gênero, geração (os velhos) e raça/etnia quanto ideológico; são aqueles que não têm valor e podem de ser descartados. ${ }^{25}$ A necropolítica reúne esses elementos letais, que são reflexíveis e têm desdobramentos na vida cotidiana e na chamada política de segurança.

O presidente e seus súditos fanáticos, os empresários oportunistas e setores das igrejas evangélicas defensores da 'teologia da prosperidade' e do 'Deus mercado" acima de tudo e de todos, na contramão de governantes de todo o mundo, advogam pelo fim da quarentema em nome de seus próprios interesses mercantis. Esses senhores, nomeadamente o 'véio' da Havan, Roberto Justos e o dono do Madero, veladamente chantageiam a população com ameaças de demissões de seus empregados, zombando do coronavírus e ostentando a empáfia de 'donos do mundo'. O dono do Madero, inclusive, declarou que cinco ou sete mil mortos não são nada se comparados aos prejuízos que a economia contabilizará. Como se todo esse desrespeito não bastasse, os donos dos impérios neopentecostais, mercadores da fé, evocam demônios e desmentem a ciência, conclamando, de forma fanática e desesperada, os seus 'fiéis-clientes' às igrejas, ao culto suicida, à procissão letal em nome do Deus, do 'Deus Mercado'. Para eles, a exemplo de Rehman Shuke, especialista do FMI, a economia também era mais importante que a quarentema - Shuke acaba de falecer de COVID 19 aos 26 anos. $^{26}$

Diante de tantas barbárie e de tantas afirmações insanas de que a economia entrará em crise e a recessão é inevitável, pergunta-se: é preferível contar os mortos ou os desempregados e subempregados precários e vulneráveis da informalidade, que existem desde sempre no neoliberalismo letal, e agora ainda mais? Vão-se as vidas e ficam as metas fiscais? Mas Bolsonaro vai na esteira da necropolítica, subestimando a letalidade provocada pela COVID-19 no Brasil e em todo mundo, ao dizer “'[...] que 'alguns vão morrer' pelo novo coronavírus, mas não se 'pode parar uma fábrica de automóveis porque tem mortes no trânsito"." ${ }^{27}$

Postas essas vicissitudes do neoliberalismo letal, vamos dar-lhes um basta! Chega de negar a seriedade da pandemia! Mais uma vez, conclamamos: “[...] chega de lutar contra as instituições; chega de negar a ciência, colocando em risco milhares de vidas humanas", não estamos dispostos a perder entes queridos em prol da acumulação de capital. ${ }^{28}$ Viver é fundamental, e a vida é muito mais do que a economia e a mais-valia sem limites dos mercados. Estamos nos referindo não apenas aos empresários supramencionados mas também à lista dos mais ricos do Brasil (segundo a revista Forbes, foram identificadas ao menos 170 pessoas com patrimônio igual ou superior a 1 bilhão de reais em 2017). ${ }^{29}$

${ }^{24}$ FERRARI, Mariana. O que é necropolítica. E como se aplica à segurança pública no Brasil. Ponte Jornalismo, [S. l.], 25 set. 2019. Disponível em: https://bit.ly/2UARCdQ. Acesso em: 20 mar. 2020.

25 BEREITO, op. cit.

${ }^{26}$ OLIVEIRA SÁ, 2020.

${ }^{27}$ LINDNER, Julia; TURTELLI, Camila. "Infelizmente, algumas mortes terão. Paciência”, diz Bolsonaro ao pedir o fim do isolamento. Folha de São Paulo, São Paulo, 27 mar. 2020. Disponível em: https://bit.ly/3dOMUkk. Acesso em: 27 mar. 2020.

${ }^{28}$ OLIVEIRA SÁ, op. cit.

${ }^{29}$ Cf.: 200 bilionários brasileiros: ranking definitivo dos mais rico do brasil. Revista Forbes, São Paulo, edição especial, 2019. Disponível em: www.forbes.com.br. Acesso em: 20 mar. 2020. 
No momento em que estamos escrevendo este editorial, assistimos, com tristeza e revolta, um grupo da burguesia irresponsável e exploradora do trabalho alheio, protegida dentro dos seus carrões, exigir que seus empregados (escravos) voltem a trabalhar para gerar riqueza, ignorando, inconsequentemente, a pandemia malévola do coronavírus. Vale lembrá-los de que o que gera riqueza não é o capital, e sim o trabalho. Sendo assim, a burguesia finalmente percebeu, mas não reconhece, que o capital imobilizado em máquinas, equipamentos, insumos e sistemas de computador não gera riqueza. Isto significa dizer que, sem os empregados, o capital torna-se inútil. Essa classe parasitária e capitalista, da qual fazem parte Luciano Hang e o outro Luciano, o dono do Madero e outros já mencionados, que não produz a não ser miséria, vive às expensas da exploração do trabalho alheio, não assume em seus discursos, nas manifestações e carreatas, que o que gera o cúmulo de capital é parcela não paga sobre o trabalho humano. Portanto, essa parte não remunerada do trabalho dos empregados (mais-valia) é acumulada pelos empregadores sob a forma de capital. Por esse motivo, eles desfilaram em algumas ruas das capitais brasileiras, mostrando para todos como funciona o capitalismo. O que a elite empresarial quer mesmo é reivindicar o seu direito, ou seja, o direito de continuar acumulando a mais-valia produzida em cima da força humana de trabalho de seus empregados. Na verdade, o que eles querem é que os trabalhadores voltem ao trabalho, pois sabem que se seus empregados morrerem isso não será problema, porque, dentro das regras do jogo capitalista, existe um exército de reserva a ser mobilizado para ocupar as vagas dos que porventura falecerem. Por isso, querem os comerciantes que os trabalhadores saiam de casa, como prega o neoliberalismo letal, e voltem para o labor. ${ }^{30}$

Num momento de crise neoliberal da economia política, que provoca uma crise no sistema de saúde (SUS), como é o caso do coronavírus, temos que, necessariamente, fazer reflexões sobre as desigualdades sociais, cujos contornos se tornam mais visíveis em momentos de pandemia. Essa situação nos incita a repensar a legitimidade da acumulação de capital e, consequentemente, da distribuição de renda destinada aos milionários e bilionários, responsáveis pelos processos de desigualdade. Isso porque saltam aos nossos olhos a precarização da saúde pública e as diferenças de qualidade entre os sistemas de saúde público e privado. Sendo assim, não podemos fazer vistas grossas aos faustosos padrões de vida das chamadas 'classes obesas', como diria Milton Santos; em situações de adoecimento, recorrem a hospitais de luxo e a clínicas de primeira categoria no mercado.

Em contrapartida, a classe trabalhadora, desempregada, subempregada e imersa no mundo destrutivo da flexibilização do trabalho, tem um padrão de vida que, em muitas das periferias, assemelha-se ao dos trabalhadores do século XIX. Está imersa na acumulação de capital, que gera distribuição desigual de riqueza. Isso significa dizer que, em pleno século XXI, o capitalismo, com suas destruições (do meio ambiente, do direito ao trabalho, da coletividade), produz desigualdades insustentáveis, arbitrárias, desumanas e injustas, ameaçando de maneira radical os valores de uma sociedade verdadeiramente democrática, assim como o presente e o futuro do planeta. A economia política capitalista, no atual estágio das políticas públicas e sociais neoliberais, promove uma injusta concentração da riqueza, penalizando a classe trabalhadora empobrecida, cortando seus direitos dia a dia e, com isso, produzindo, reproduzindo e acentuando as desigualdades sociais, ao mesmo tempo em que se alimenta delas.

Diante de todo drama social, político e sanitário que assola o mundo, nossa posição, no que tange a essa crise no Brasil, advoga pela imediata suspensão do pagamento da dívida, seguida por uma auditoria cidadã, a fim de destinar recursos para o combate ao coronavírus e fazer com que o país estanque a sangria de suas riquezas, costumeiramente direcionadas à manutenção do capitalismo, que, no seu parasitismo especulativo, privilegia a acumulação de capital, em detrimento

${ }^{30}$ RAMOS FILHO, Wilson. Nudez. Jornal GGG, [S. l.], 28 mar. 2020. Disponível em: https://bit.ly/2UyUhEK. Acesso em: 28 mar. 2020. 
da saúde e da vida dos trabalhadores. ${ }^{31}$ Além disso, pensamos ser de fundamental importância elaborar alternativas anticapitalistas para enfrentar a luta precatória, ou seja, o não pagamento da dívida pública nesse momento de desconstrução do neoliberalismo. Também é de igual relevância a imediata taxação das fortunas acumuladas dos mais ricos. ${ }^{32}$ Esse tipo de ação, diante do número de pessoas ricas no Brasil, tal como apresentado pela Forbes, seria um procedimento mais justo do que cortar o salário dos servidores públicos. A cota de 'sacrifícios', agora, em tempos difíceis, deveria caber aos ricos, aos milionários, aos bilionários do Brasil.

Nesse viés, cumpre "repensar o imposto progressivo sobre a renda". ${ }^{33}$ Isto significa que, se quisermos diminuir as desigualdades sociais, devemos voltar nossos olhares críticos para os impostos, as taxas e as arrecadações dos mais ricos, além de instituir o imposto progressivo sobre heranças. Sendo assim, em tempos de pandemia e de neoliberalismo letal, poderemos extrair lições para o presente e o futuro. ${ }^{34}$ Com esses procedimentos teórico-metodológicos e políticos, pretendemos investigar não apenas as causas e consequência das desigualdades sociais tendo como eixo a pobreza, mas, a partir de pesquisas, apontar quem são os ricos do Brasil e como eles acumularam tanto capital até a presente data. Então a pergunta que se coloca é: quem são os ricos? Como defini-los? De onde vêm seus patrimônios e heranças? Essas perguntas se justificam porque a combinação de poder político e econômico é o que faz com que os ricos sejam um dos grupos da sociedade com maior capacidade de influenciar os rumos da política e do desenvolvimento nacional em seu proveito, explorando e oprimindo a classe trabalhadora. Por isso é tão importante estudar este grupo, tão influente e poderosos, pois, com a análise das características e determinantes da riqueza, torna-se possível compreender e analisar profundamente quem controla a sociedade brasileira e em que medida seus interesses vão de encontro às reais necessidades da massa da população. ${ }^{35}$ Essas questões são seminais, pois, de acordo com Mészáros, “[...] o sistema do capital não tem limites para a sua expansão, convertendo-se numa processualidade incontrolável e profundamente destrutiva". ${ }^{36}$

Seguramente, num momento em que a polarização por parte das elites empresariais se constitui na oposição entre defender as vidas e/ou a economia, as reflexões de Mészáros são oportunas. Diante dessa posição desumana e descomprometida com a vida dos cidadãos, torna-se imprescindível apregoar que não deve haver contradição entre a proteção da economia e a proteção da saúde pública. Isso porque a recessão econômica decorrente da pandemia será global e inevitável, como já se pode constatar em alguns países, como a Itália, os EUA, a França, a Espanha, a China e outros. Nesses termos, precisamos imediatamente de medidas de proteção social, especialmente o provimento de renda mínima para trabalhadores informais e o complemento de renda para populações vulneráveis, a exemplo do que outros países estão fazendo. É mister lembrar de que a proteção econômica é um dever do Estado, que garantirá tanto a subsistência dos beneficiários como a preservação de um nível básico de consumo, protegendo a vida da população e a economia, inclusive os pequenos comércios. Do que devemos ter clareza é que a economia brasileira não se confunde com os interesses de determinados grupos econômicos. ${ }^{37}$

${ }^{31}$ ANDESUFSC. Nota da Diretoria da ANDESUFSC a favor da VIDA e CONTRA o governo Bolsonaro. Florianópolis, 25 de março de 2020. Disponível em: https://bit.ly/3dRTBlv. Acesso em: 20 mar. 2020.

${ }^{32}$ PIKETTY, Thomas. O capital no século XXI. Rio de Janeiro: Intrínseca, 2014.

${ }^{33}$ CATATTANI, Antônio David. Riqueza e desigualdade na América Latina. Porto Alegre: Zouk, 2010.

${ }^{34}$ PIKETTY, op. cit., p. 480.

35 PIKETTY, 2014.

${ }^{36}$ MÉSZÁROS, 2011 apud CATATTANI, 2010, p. 83.

${ }^{37}$ UNIVERSIDADE DE SÃO PAULO. Nota à imprensa da Congregação da Faculdade de Saúde Pública da USP sobre a evolução da pandemia do COVID-19. FSP-USP, São Paulo, 27 mar. 2020. Disponível em: https://bit.ly/2ysxylp. Acesso em: 27 mar. 2020. 


\section{Pandemia, resiliência e resistência ativa}

Neste momento de crise do neoliberalismo, há duas tarefas: uma tarefa humanitária e de saúde pública, a erradicação da COVID-19, e a outra, a destituição desse vírus mental chamado Bolsonaro! Assim, enfrentamos o desafio de destruir dois vírus: o coronavírus e o bolsonavírus. Diante dessas circunstâncias, nós, editores, somos da opinião de que devemos manter a resistência e a organização contra qualquer ataque aos direitos da classe trabalhadora, principalmente levando em conta que o governo aproveita a pandemia para precarizar ainda mais as políticas públicas e sociais, suprimindo direitos, cortando salários, elevando impostos e adotando outras medidas igualmente deletérias com chantagens ao Congresso nacional e, mesmo, com a cumplicidade de parte desse.

Esse procedimento é deveras importante, haja vista a gravíssima crise econômica e de saúde pública que assola a humanidade em decorrência do avanço da COVID-19. No Brasil, temos que lidar com o genocida funcional, que age de acordo com os interesses e a reorganização do capital internacional e nacional, assumindo descaradamente a defesa do extermínio de parte da população trabalhadora. Ele precisa ser urgentemente interditado, antes que se percam mais vidas.

A tarefa é árdua, porque previsão para os meses de abril e maio é de aceleração da curva de contágio no país, com centenas ou milhares de óbitos. O Presidente da República, o "neurônio assassino', de forma irresponsável, provavelmente cometendo um crime de lesa-humanidade, contrapõe-se às medidas sanitárias adotadas no mundo inteiro, endossadas por renomados cientistas, desdenhando dos dados concretos sobre o número de mortes e do acúmulo de pesquisas que atestam a periculosidade da COVID-19. Além do mais, ironiza e desautoriza as medidas de governo de estados e municípios, que orientam os cidadãos a permanecerem em suas casas. O governo federal propõe cortes orçamentários que precarizam a vida da população em geral, principalmente os trabalhadores da área de prestação de serviços informais, disponibilizando, a título de 'ajuda', ínfimos recursos para os trabalhadores, o SUS e as universidades públicas, locus principal de produção de ciência para o combate da pandemia. ${ }^{38} \mathrm{Em}$ meio a todas essas parcas medidas, tem como prioridade financiar os banqueiros e os capitalistas financiadores de sua campanha. Como se toda essa destruição e a omissão por parte do Estado não bastassem, tenciona reduzir o salário de servidores, inclusive dos que estão na linha de frente para vencer a COVID-19, a maior crise econômica e sanitária do mundo. Trata-se, portanto, de transferir a responsabilidade à classe trabalhadora, que abrange aqueles e aquelas que se encontram abaixo da linha da pobreza, como os mais vulneráveis e precarizados pela economia hiperneoliberal, que vivem nas favelas e palafitas, nas periferias das grandes e médias cidades (idosos, negros, quilombolas, indígenas e pobres), os quais, se o Estado Mínimo não lhes socorrer, serão lançados às estatísticas dos próximos óbitos no país.

Com efeito, a crise do capital traz consigo a crise do mundo do trabalho, no Brasil em todo o planeta. Essa questão pode ser melhor aprofundada a partir do livro O privilégio da servidão voluntária, de Ricardo Antunes. Nessa linha, a ideia é fazer reflexões a respeito dos impactos do coronavírus sobre a situação de trabalhadoras e trabalhadores que vivem o contexto de legitimação e expansão do trabalho intermitente, assim como o sobre crescimento do trabalho digital. E toda a preocupação dos intelectuais e políticos de esquerda tem sido justamente com os trabalhadores precarizados e autônomos, sobretudo os desempregados, que, no âmbito da lei de terceirização e das reformas trabalhista e da previdência, agora sentem os efeitos dessas políticas, no limiar da pandemia do novo coronavírus.

${ }^{38}$ ANDESUFSC, mar. 2020. 
Vale lembra que, desde Temer (2016), a classe trabalhadora vem sofrendo a amarga experiência de devastação de seus direitos, que se agravou ainda mais no governo Bolsonaro. Num cenário de pandemia, essa situação fica mais dramática, pois o que temos hoje é uma massa imensa de trabalhadores intermitentes, que não têm outro caminho senão trabalhar por oito, dez, doze e até 14 horas ao dia. O mais grave é que, se não trabalharem, eles não dispõem de dinheiro para sustentar suas famílias e, trabalhando precariamente, não têm direitos. O Estado capitalista brasileiro não lhe dará direitos; no máximo, esmolas. Isso tudo se chama 'escravidão digital', no caso, sobretudo, dos aplicativos dia (Uber, Rappi e Ifood, etc.). Essa parcela da classe trabalhadora está aprisionada nas teias da servidão da informalidade, predominante nessas plataformas digitais. Em desfavor desses trabalhadores, há uma enorme manipulação na interpretação das leis trabalhistas por parte do Estado, cujo argumento enquadra os uberizados na categoria de prestadores de serviços, portanto não são assalariados e sem os direitos devidos aos empregados formais. ${ }^{39}$

O trabalho intermitente agora é 'legal' e 'formal'. Mas é uma legalidade fajuta, que legitima a ilegalidade. Bolsonaro fez o que o Temer não conseguiu: desmontou a previdência. Em vista disso, há uma massa imensa de homens e mulheres que margeia a formalidade, recorrendo ao cadastro de Micro Empreendedor Individual (MEI), numa tentativa de tapar o sol com a peneira. Quem trabalha 12 horas por dia não é microempresário, mas sim um ‘proletário de si mesmo'. São 5 milhões e meio de jovens trabalhadores de aplicativos que vão entregar alimentação enquanto todo mundo estiver recolhido em casa, em isolamento social? Pelo visto, estamos vivendo em uma sociedade de escravos, vítima de uma corrosão ilimitada do trabalho, e a resultante disso serão indivíduos sem previdência nem sistema de saúde. A pergunta que fica é: como farão se contraírem a COVID-19? Quem cuidará deles, uma vez que são prestadores de serviços sem direitos previdenciários e vínculo empregatício algum, ou seja, são trabalhadores informais e precários que são jogados nas ruas, mais duramente os imigrantes e os negros. ${ }^{40}$

Além dos trabalhadores que atuam em aplicativos, há também o comércio informal, que, às vezes, acolhe imigrantes e outras parcelas da população mais vulneráveis, econômica e socialmente falando. Esses também sofrem com a pandemia. São a parcela mais precarizada do sistema, embora o desempregado esteja numa situação ainda mais dramática do que a deles, porque está no desespero completo, não raro doente de depressão e entregue às drogas e ao alcoolismo. Acrescente-se a isso o fato de que os trabalhadores informais das ruas são uma espécie de trabalhador subutilizada, vão para o trabalho informal porque não encontram vagas no mercado formal. E quando desistem, engrossam as estatísticas das chamadas populações de rua. No Brasil, há aproximadamente $40 \%$ da população ocupada na informalidade; em várias capitais do Nordeste, este índice chega a $50 \%$ e $60 \% .^{41}$

Uma reflexão se faz necessária neste editorial: se o mercado formal, o mundo da valorização do capital, está parado em amplitude global, e a bolsa de valores vem despencando a níveis espetaculares, imaginem o drama dos trabalhadores do mercado de trabalho informal. Ademais, pesa ainda sobre esses trabalhadores a ausência de um sistema previdenciário que os abarque e, nesses termos, de um serviço público de saúde capaz de atendê-los. O Brasil tem o SUS, que é uma experiência muito importante, mas ele vem sendo destroçado. Some-se a tudo isso o fato de a Emenda Constitucional (EC) n ${ }^{\circ} 95$, que proíbe o aumento de recursos para a saúde, a educação e a previdência, aprovada durante o governo terceirizado de Michel Temer, não permitir que, num quadro de agravamento da epidemia, os trabalhadores cheguem aos hospitais e tenham atendimento, mesmo se contaminados com o coronavírus, o que os levará, fatalmente, a contaminarem seus parentes. ${ }^{42}$

${ }^{39}$ DIAS, Helena. "Chega uma hora que a saída é ao modo do filme Bacurau, entende?, adverte Ricardo Antunes. Marco Zero, [S. l.], 25 mar. 2020. Disponível em: https://bit.ly/2ysjeJB. Acesso em: 26 mar. 2020.

${ }^{40}$ DIAS, 2020.

41 Ibid.

42 Ibid. 
Em meio a todas essas agruras do mundo do trabalho em tempos de neoliberalismo, uma posição coletiva plausível por parte da sociedade civil, dos partidos políticos, de intelectuais e sindicalistas é exigir do governo que estimule as pessoas a ficar em casa, mas que o Estado, pelo menos durante o período de quarentena, apresente uma política que tenha como bandeiras, como já evocamos anteriormente, medidas não apenas paliativas. Portanto, o que deve estar em pauta é o fim da $E C \mathrm{n}^{\circ}$ 95, a fim de acabar com o limite do orçamento para a saúde, a educação e a previdência. Medidas paliativas são inaceitáveis e inegociáveis. Não basta distribuir kits de higiene; o que se quer é que o Estado lave as mãos impregnadas de mercado, deixe de pagar a dívida externa e amplie as verbas do serviço público de saúde (SUS), visando à destruição desses três vírus: Bolsonaro, o neoliberalismo e o coronavírus. ${ }^{43}$

É importante esclarecer: esta tragédia não é causada pelo coronavírus; a pandemia apenas a explicita e amplifica exponencialmente. Porque a tragédia antecede a atual situação, se comparamos o Brasil com países escandinavos, como Suécia e Dinamarca, onde os índices de trabalho informal são menores, as pessoas se guardam em casa e são justamente remuneradas e, nesse interim, as verbas do serviço público de saúde são ampliadas.

Neste momento, o mais importante é preservar e salvar vidas, considerando-se que elas se sobrepõem às metas fiscais. Sem sombra de dúvidas, a desigualdade social é naturalizada e tratada como herança, e não como uma construção histórica consubstanciada nas políticas públicas promovidas pelo Estado Mínimo (privatização dos serviços públicos e redução do tamanho do Estado). Nesse aspecto, para os economistas neoliberais, as desigualdades são tidas como uma consequência inevitável da lógica dos mercados. Para esses senhores, uma vez que o sistema é assim, deve-se fazer gestões que, no máximo, mitiguem o empobrecimento, com políticas de 'inclusão' social meramente compensatórias, tal como constam nos objetivos desse tipo de governo. ${ }^{44}$

$\mathrm{Na}$ contramão dessas políticas engendradas pelos economistas neoliberais, encontram-se as políticas de esquerda, a saber: as social-democratas e as de base socialista, que propõem políticas para além da agenda neoliberal. Apesar de algumas diferenças ideológicas e econômicas em entre si, elas propugnam o fortalecimento do Estado e a formulação de políticas públicas capazes de reduzir a desigualdade, oferecendo serviços públicos para todos (ex.: fortalecimento do SUS e da educação pública gratuita, de qualidade e socialmente referenciada). Assim, os bens comuns adquirem a qualidade de salário indireto e de políticas de inclusão para os mais vulneráveis. Todavia, é preciso valorizar as bases socialistas mais radicais e de superação, que propõem uma agenda de políticas públicas e sociais para além do capital. Essa reflexão, porém, só virará ação quando a esquerda tiver como mira o efetivo enfrentamento da propriedade privada dos meios de produção. Isso terá que ocorrer na base da luta e na determinação de não mais otimizar o lucro das empresas, buscando o comando do Estado. É preciso superar a máxima neoliberal de que as políticas públicas e sociais não cabem no orçamento público e também a ideia de saúde na perspectiva da mercadoria, declarando-a direito humano e social cuja prestação incumbe ao Estado. Por tudo isso, torna-se urgente, em tempos de coronavírus, lutar para a derrubada da EC n ${ }^{\circ} 95$ (a PEC do fim do mundo), que impôs o teto de gastos durante trinta anos. Contudo, para que isso seja factível, é preciso criar uma nova democracia, para além da democracia burguesa, para além da democracia liberal. ${ }^{45}$

\footnotetext{
${ }^{43}$ DIAS, 2020.

44 BAVA, Silvio Caccia. Editorial: Desigualdade. Le Monde Diplomatique, [S. l.], Ano 13, n .15, mar. 2020 , p. 3. Disponível em: https://bit.ly/39xFLRV. Acesso em: 25 mar. 2020.

${ }^{45}$ BAVA, op. cit.
} 
Quando se pretende responder à questão se 'o neoliberalismo acabou?', apesar de sua crise pelo mundo, em especial na América Latina, necessário se faz reconhecer que ele ainda é acionista dos grandes conglomerados financeiros e industriais, que, muitas vezes, assumem seu controle e direção, haja vista a imensa quantidade de recursos públicos entregue ao grande capital. Todo esse imbróglio vem ocorrendo num cenário de extrema turbulência e disputas pelo poder político, em nível local, nacional e internacional, em que a ameaça de um crash econômico global atemoriza a todos. A crise rompeu paradigmas, e os representantes do grande capital forçaram a adoção, por parte de governos, de medidas que podem prefigurar mudanças mais profundas e dramáticas para a classe trabalhadora. Nesse sentido, vale lembrar que o Estado, sob a égide do projeto neoliberal, vem, de maneira vertiginosa, assumindo o controle do sistema financeiro, por meio de um pacto com os banqueiros, das privatizações e da entrega (de mão beijada) do patrimônio para o capital internacional, comprometendo assim a soberania nacional. ${ }^{46}$

Quando se trata de resistência diante do neoliberalismo autoritário, imposto pelo governos da América Latina e do mundo, que ignoram o desespero, o sofrimento, a pobreza extrema e a exclusão das populações das política públicas e sociais, um dos caminhos a se tomar é a desapropriação das riquezas, ou seja, dos recursos naturais, do petróleo, do gás, da água, da terra, das florestas. Devolvêlas aos seus legítimos proprietários, já que pertenciam a todos antes de serem privatizadas. Essas ações podem parecer utópicas, sem condições objetivas de implementação, mas, recentemente, em vários países, a nacionalização de empresas, mesmo com seus problemas e contradições, tornou possível ao Estado reforçar seu controle sobre setores estratégicos, como eletricidade, telefonia, indústria petrolífera, entre outros. ${ }^{47}$

Com esse tipo de entendimento, consideramos que o confinamento, em tempos de Pandemia, é um bom momento para entender e questionar o que realmente importa: o anacronismo do neoliberalismo, articulado com o autoritarismo e o fascismo, que sobrevive ceifando vidas, ao espalhar o ódio de classe, raça/etnia, gênero, cultura e geração, o terror, a violência e a miséria através de políticas centradas na necropolítica.

É tempo de construir reflexões-ações e anúncios de resistências e superações; tempo de exercitar o melhor de cada um para consigo mesmo e para com os outros: a coletividade, a solidariedade, a generosidade, a gentileza, a vida sem exploração e longe do consumismo, o reconhecimento para com aqueles que estão trabalhando para conter o avanço da catástrofe. E tempo também para a autorreflexão, a autocrítica e as críticas contundentes ao capitalismo; tempo de não separar política, saúde e educação; tempo de diálogo e, sem dúvida, de reflexão sobre o sentido de viver em comunidade e da vida humana no planeta Terra, já que ela tem sido cotidianamente desprezada de modo narcísico e inconsequente. Em resumo, "esse é o momento decisivo para a crítica ao neoliberalismo", considerando-se que, embora esse sistema obsoleto piore "o viver (em sentido econômico, social, cultural e nos demais âmbitos da vida) de muita gente - ele também se apresenta como inviável quando se trata de sobreviver em sentido biológico".

O capitalismo neoliberal

[...] é em primeiro lugar uma teoria das práticas político-econômicas que propõe que o bem-estar humano pode ser mais bem promovido liberando-se as liberdades e capacidades empreendedoras individuais no âmbito de uma estrutura institucional

\footnotetext{
46 BAVA, 2020.

${ }^{47}$ Ibid., loc. cit.
} 
caracterizada por sólidos direitos de propriedade privada, livres mercados e livre comércio. O papel do Estado é criar e preservar uma estrutura institucional a essas práticas; o Estado tem que garantir, por exemplo, a qualidade e a integridade do dinheiro. $^{48}$

Nesse sentido, a mão do mercado, amparada pela 'integridade do dinheiro' - garantia da reprodução do capital -, é capaz de tudo para a manutenção de seu ethos opressor e explorador. E, quanto a essa questão, os empresários capitalistas também sabem que o Estado "[...] deve garantir o estabelecimento das estruturas e funções militares, de defesa, da polícia e legais requeridas para garantir os direitos de propriedade individuais e para assegurar, se necessário pela força, o funcionamento apropriado dos mercados". ${ }^{49}$ Por outro lado, o processo de neoliberalização envolve muita 'destruição criativa'; e isso não somente dos antigos poderes e estruturas institucionais, chegando mesmo a abalar as estruturas tradicionais de soberania do Estado e, além do mais, as divisões do trabalho, das relações sociais, da promoção do bem-estar social, das combinações de tecnologias, dos modos de vida e de pensamento, das atividades reprodutivas, das formas de ligação à terra e dos hábitos do coração. ${ }^{50}$ Em síntese, o neoliberalismo tem como um de seus pressupostos "[...] uma ética em si capaz de servir de guia a toda a ação humana e que substitui suas crenças éticas antes sustentadas". Ele advoga "[...] a significação das relações contatuais no mercado e sustenta que o bem social é maximizado se se maximizam o alcance e a frequência das transações de mercado, visando enquadrar todas as ações humanas no domínio do mercado". ${ }^{51}$

Essas considerações são fulcrais, pois estamos em mais uma crise neoliberal, agravada pela pandemia do coronavírus. Na verdade, estamos triplamente em crise: de um lado, despontam as crises cíclicas do capital, que se manifestaram e ainda se manifestam em nível planetário. ${ }^{52}$ De outro lado, no Brasil, a crise atual se expressa pelas ingerência do neoliberalismo em desmonte, um neoliberalismo autoritário e nazifascista. E, por fim, pela pandemia da COVID-19, cuja proliferação pelo mundo tem mostrado a dupla face genocida do neoliberalismo, sobretudo o seu fracasso.

Nesse sentido, podemos afirmar, corroborando as opiniões de Noam Chomsky, que "[...] o colapso dos sistemas de Saúde diante da crise se deve aos governos neoliberais de muitos países", 53 entre os quais um dos maiores culpados é o presidente dos EUA, Donald Trump, por minimizar a situação e arriscar a vida de milhões de pessoas naquele país. O filósofo e linguista acrescenta que

No geral, esta crise é outro exemplo importante de falha de mercado, assim como a ameaça de uma catástrofe ambiental. O governo e as multinacionais farmacêuticas sabem há anos que existe uma alta probabilidade de uma pandemia grave, mas como não é bom para os lucros o preparo contra isso, nada foi feito. ${ }^{54}$

Na opinião dele, Trump e seu governo minimizaram a gravidade da crise, numa atitude que foi replicada e aumentada pela mídia, o que levou muitas pessoas a parar de tomar as precauções básicas. Continuando suas críticas às condições gerais da pandemia, Chomsky afirmou: "O ataque neoliberal deixou os hospitais despreparados. Um exemplo é a quantidade de leitos para tratamento, que foram removidos em nome de 'eficiência'." 55

${ }^{48}$ HARVEY, David. O neoliberalismo: história e implicações. São Paulo: Loyola, 2012, p. 3.

${ }^{49}$ Ibid., loc. cit.

${ }^{50}$ Ibid., loc. cit.

${ }^{51}$ Ibid., p. 4.

52 DANTAS, Eric Gil. Crises econômicas: os ciclos sincronizados do capitalismo. Pragmatismo político, [S. l.], 2 fev. 2016. Disponível em: https://bit.ly/2JtTYow. Acesso em: 25 mar. 2020.

${ }^{53}$ NOAM Chomsky diz que a crise do coronavírus prova o fracasso do neoliberalismo. Diário do Centro do Mundo,

São Paulo, 24 mar. 2020. Disponível em: https://bit.ly/2UBpjMv. Acesso em: 26 mar. 2020

${ }^{54}$ Ibid.

${ }^{55}$ Ibid. 


\section{Sobre essa edição...}

Um detalhe deve chamar a atenção dos leitores dessa edição: o número de textos publicados é bastante superior ao que vínhamos veiculando em nossas edições anteriores.

De fato, quanto ao procedimento de preparação dos originais a serem publicados e montagem do sumário, a revista utilizou há até pouco tempo o modelo de diagramação, contratado a uma empresa de serviços editoriais. Os seus custos elevados representavam uma trava orçamentária para que pudéssemos publicar mais textos e mais edições ao longo do ano. Em 2019, fizemos a transição para o modelo por templates, em que os próprios autores, à medida que tem seus trabalhos aprovados, os preenchem e enviam para essa editoria, que revisa, gera os pdfs e os publica com o apoio dos nossos parceiros do Portal de Periódicos da BU/UFSC. Isso permitiu que, no ano passado, a título de experiência com o novo modelo, nós ampliássemos nossa circulação para trimestral e aumentássemos para vinte (20) o número de textos em cada edição.

No presente ano, já com certa estabilidade das novas rotinas editoriais decorrentes do modelo por templates, nos sentimos mais seguros para aumentar ainda mais o número de textos publicados a cada edição e, assim, reduzir o tempo entre a aprovação e a publicação de um artigo.

É o que estamos fazendo na presente edição (v.32 n.61). Com dezoito (18) artigos originais e mais quinze (15) de revisão (seção Porta Aberta), estamos colocando à disposição da comunidade da área cerca de 50\% dos textos submetidos e aprovados ainda em 2019 - mantendo a norma de publicar primeiro os mais antigos na ordem cronológica de submissão.

A próxima edição (v.32 n.62), a ser publicada ainda neste primeiro semestre de 2020, deve dar vazão aos demais textos que restaram aprovados do ano de 2019, zerando assim esse "passivo".

Desta forma, pretendemos dar uma resposta mais célere ao justo interesse de autores e leitores, que tem o direito de ter acesso à produção acadêmica com maior rapidez, sem descuidar, é claro, do rigor dos processos avaliativos e editoriais que caracterizam nosso periódico.

Mas não paramos por aqui. A exemplo de várias outras revistas, inclusive da nossa área, que já o adotaram, a possível transição da Motrivivência para o modelo de publicação contínua está sendo considerado por nossa comissão editorial. Sabemos das suas vantagens, sob diferentes aspectos, sobretudo pela agilidade que possibilita ao fluxo submissão-avaliação-publicação, reduzindo assim esse gargalo comum a todos os periódicos científicos. Para tanto, é necessário concatenar uma nova rotina interna à revista, envolvendo nossa equipe editorial e os revisores de metadados do Portal de Periódicos da BU/UFSC, até mesmo para evitar-se os erros de indexação que vem sendo observados em algumas bases de dados que importam automaticamente os metadados dos artigos publicados como prévia da próxima edição, sem as posteriores correções. Talvez, em breve possamos estar informando mais novidades aos leitores da revista.

É importante registrar que a Motrivivência, cujo projeto editorial é "à moda antiga", como sempre brincamos, tem responsabilidade com seus colaboradores, autores e leitores e, nesse sentido, vem implementando com segurança - talvez com vagar para muitos - inovações tanto tecnológicas quanto de normas que garantam boas práticas editoriais, éticas, acadêmicas, políticas e sociais. Esse é nosso compromisso e temos atuando incessantemente para que a revista se modernize sem perder seus princípios e assim seja, sempre e cada vez mais, reconhecida pela comunidade da Educação Física, Esporte e Lazer.

Nesse sentido e em tempos de transições, estamos dedicando a seção Homenagens dessa edição para destacar quatro companheiros da Motrivivêcia que foram muito importantes na passagem da revista para o modelo digital na plataforma SEER/Open Journal System, nos idos de 2008: os professores Ari Lazzarotti Filho, Iracema Munarim, André Marsiglia Quaranta e Victor de Abreu 
Azevedo. Aos quatro e a todos/as que naquela ocasião e desde então vem contribuindo na "cozinha técnica" da revista, os nossos mais sinceros agradecimentos e eterno reconhecimento. Valeu muito!

Nossa capa é mais uma contribuição inestimável do professor e fotógrafo baiano Paulo Lima. Com a sua sensibilidade, ele nos brinda com uma imagem que é, ao mesmo tempo, impactante, misteriosa e simbólica. Em tempos de coronavírus, em que o uso de máscaras de proteção facial vem se tornando intensivo, a máscara retratada na capa se apresenta como um contraponto desafiador: enquanto a máscara sanitária esconde nariz e boca, deixando à vista apenas os olhos ("a janela da alma", para Leonardo Da Vinci), a máscara captada pelo olhar sensível do artista evoca o seu contrário: mostra uma boca e um nariz lisos, quase assépticos (ou ascéticos?), mas sem olhos, portanto, não vê o mundo nem mostra a sua alma... Acreditamos que essa metáfora se mostra muito pertinente com o que nosso editorial busca explicitar em relação ao neoliberalismo letal, à necropolítica, ao bolsonavírus e a sua legião de idiotas não empáticos com a dor e o sofrimento.

Para concluir, deixamos alguns trechos das músicas Comportamento geral, de Gonzaguinha, e Sol de primavera, de Beto Guedes. Esta última vem acompanhada de uma reflexão sobre texto de Mauro Iasi, intitulado Quando entrar setembro.

Você deve notar que não tem mais tutu e dizer que não está preocupado

Você deve lutar pela xepa da feira

e dizer que está recompensado

Você deve estampar sempre um ar de alegria e dizer: tudo tem melhorado

Você deve rezar pelo bem do patrão e esquecer que está desempregado

Você merece, você merece Tudo vai bem, tudo legal Você merece, você merece Você merece, você merece Tudo vai bem, tudo legal

(Gonzaguinha)

Uma nova canção Que venha trazer Sol de primavera Abre as janelas do meu peito

A lição sabemos de cor

Só nos resta aprender

(Beto Guedes)

"Quando entrar setembro e a boa nova andar nos campos", "[...] para mim, o que me agradaria, uma vez passada esta crise, é que nossas casas fossem novamente habitadas por seres humanos que 
reaprenderam a valorizar o que realmente é importante"56 e que tenhamos aprendido a desconstruir o neoliberalismo autoritário e letal, construindo, em seu lugar, uma nova sociedade mais solidária e humana, para além do capital, ou seja, pela abolição das desigualdades sociais e de classe.

Desejamos uma leitura apurada e crítica e muita coragem na luta contra a COVID-19 e o neoliberalismo letal! Temos que tentar barrar isso tudo, pois "Somos vítimas de uma combinação canhestra em que a ignorância se associa à ideologia e aprofunda a pobreza e o desnível social, sempre a nos enganar com um canto de sereia marcial". ${ }^{57}$ Temos que lutar solidária e coletivamente, sem soltar a mão de ninguém - de longe, principalmente,

[...] nessa hora em que o antipresidente desrespeita cotidianamente a vida e o futuro de nosso povo, agarrado como craca nos cascos de um navio a pique, mais do que revolta, surge nos homens de bem uma profunda vergonha de termos compactuado com a mentira e a ideologia; hoje, parte da sociedade brasileira é vítima de sua própria cegueira. De mãos dadas com seu carrasco-redentor, caminha impotente para sua hora final. Docilmente, apesar de alertada pelo próprio carrasco de que sua salvação depende apenas de sua determinação em salvar-se. ${ }^{58}$

Nesta hora de isolamento social, mas não de isolamento político, crítico e propositivo, tempo de desconstrução, a nossos corpos produtivos, que produzem mais-valia para o capital, só resta proclamar para todo o mundo os versos do poeta nicaraguense Luis Enrique Mejía Godoy: Quedate en casa!

Quedate en casa pero no te aislés del mundo Leé un libro y viajarás por lugares insospechados Escuchá una canción y dejá que la música te invada los sentidos

Sentirás entonces que abrazás intensamente a miles de seres humanos que tienen sed de paz como tus ojos.

Leé un poema y dejá que las palabras te acaricien

ahora que desde tu casa encendés el fuego de tu corazón para compartir la noche con tu sombra.

Quedate en casa pero salí al patio y mirá la luna

56 IASI, Mauro. Quando entrar setembro. Blog da Boitempo, São Paulo, 20 mar. 2020. Disponível em: https://bit.ly/2XaF6nf. Acesso em: 20

57 OLIVEIRA SÁ, Thiago Antônio. Neoliberalismo letal. Jornal GGG, [S. l.], 26 mar. 2020. Disponível em: https://bit.ly/2Uy1pRO. Acesso em: 26 mar. 2020.

${ }^{58}$ BAHADIAN, Adhemar. O século XXI pede passagem. Jornal do Brasil, Rio de Janeiro, 29 mar. 2020. Disponível em: https://bit.ly/3dLTiZL. Acesso em: 29 mar. 2020. 
que sigue siendo hermosa aún hoy que urgentemente busco en los estantes de la memoria aquel viejo bolero que cantaba mi padre en aquellos años en que una peste amenazaba al mundo.

Quedate en casa quizás este sea el tiempo necesario para encontrarte con vos mismo y así entiendas que requerimos del otro para vivir.

Hablá a solas con tu corazón y tu conciencia no te arrodilles jamás frente a la adversidad Aquí está mi abrazo distante pero no ausente Esto no es un castigo de Dios es un chance para entender que es necesario cambiar

Nunca es tarde y nada es para siempre.

Quedate en casa que mañana abriremos las puertas de par en par para que entre el sol y con él todos los que no se rindieron en esta enorme prueba de amor y de resiliencia.

\author{
FORA, BOLSONARO JÁ! É MELHOR VOCÊ JAIR-EMBORA! \\ LULA LIVRE! MARIELE PRESENTE! \\ DITADURA, NUNCA MAIS!
}

Florianópolis, outono de 2020.

Maurício Roberto da Silva, Giovani De Lorenzi Pires, Rogério Pereira

Editores 